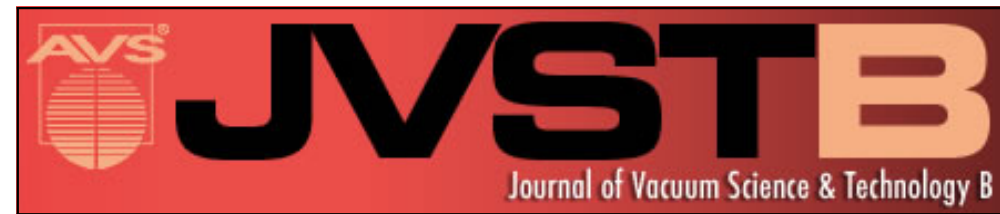

\title{
Hybrid nanofabrication processes utilizing diblock copolymer nanotemplate prepared by self-assembled monolayer based surface neutralization
}

Su-Jin Kim, W. J. Maeng, S. K. Lee, D. H. Park, Sung Hwan Bang, Hyungjun Kim, and Byeong-Hyeok Sohn

Citation: Journal of Vacuum Science \& Technology B 26, 189 (2008); doi: 10.1116/1.2830693

View online: http://dx.doi.org/10.1116/1.2830693

View Table of Contents: http://scitation.aip.org/content/avs/journal/jvstb/26/1?ver=pdfcov

Published by the AVS: Science \& Technology of Materials, Interfaces, and Processing

\section{Articles you may be interested in}

Curing process of silsesquioxane in self-organized diblock copolymer template

J. Vac. Sci. Technol. B 27, 3025 (2009); 10.1116/1.3256232

Si-containing block copolymers for self-assembled nanolithography

J. Vac. Sci. Technol. B 26, 2489 (2008); 10.1116/1.2981079

Micropatterning organosilane self-assembled monolayers with plasma etching and backfilling techniques

J. Vac. Sci. Technol. B 23, 354 (2005); 10.1116/1.1861041

Nanoscopic templates using self-assembled cylindrical diblock copolymers for patterned media J. Vac. Sci. Technol. B 22, 3331 (2004); 10.1116/1.1815301

Combining advanced lithographic techniques and self-assembly of thin films of diblock copolymers to produce templates for nanofabrication

J. Vac. Sci. Technol. B 18, 3530 (2000); 10.1116/1.1313572

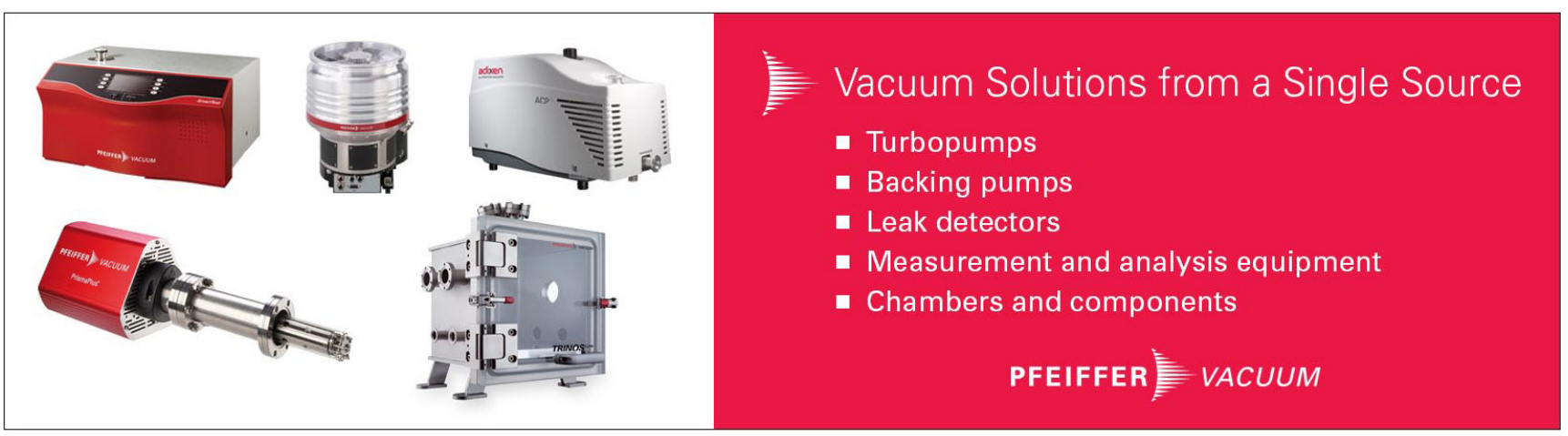




\title{
Hybrid nanofabrication processes utilizing diblock copolymer nanotemplate prepared by self-assembled monolayer based surface neutralization
}

\author{
Su-Jin Kim, W. J. Maeng, S. K. Lee, D. H. Park, Sung Hwan Bang, and Hyungjun Kimª) \\ Department of Materials Science and Engineering, Pohang University of Science and Technology \\ (POSTECH), Pohang 790-784, Korea \\ Byeong-Hyeok Sohn \\ Department of Chemistry, Seoul National University, Seoul 151-742, Korea
}

(Received 23 August 2007; accepted 7 December 2007; published 16 January 2008)

\begin{abstract}
Nanostructures including nanohole and metal dot arrays were fabricated by hybrid processes combing self-assembled diblock copolymer and conventional semiconductor processes. The interfacial energy between polystyrene- $b$-polymethylmetacrylate (PS- $b$-PMMA) diblock copolymer and substrate surface was controlled by employing a self-assembled monolayer (SAM), resulting in a polymer template with well-ordered cylindrical nanohole array. The nanohole sizes were controlled within 10 to $22 \mathrm{~nm}$ in diameter using block copolymers with different molecular weights. The PS nanotemplates were fabricated on various substrates, including oxides, nitrides, and poly-Si. Nanohole pattern was transferred by dry etching process, producing inorganic nanohole templates. Also, gold nanodot arrays with diameter smaller than $10 \mathrm{~nm}$ were fabricated through lift off process. () 2008 American Vacuum Society. [DOI: 10.1116/1.2830693]
\end{abstract}

\section{INTRODUCTION}

With devices scaling into the nanoscale regime, the ability to produce nanodevices becomes critically dependent upon the resolution of lithography. Although a number of "next generation" lithography techniques are under investigation, the nanopatterning for feature size smaller than $20 \mathrm{~nm}$ has no clear solution yet. As an alternate way of nanopatterning, the bottom-up process based on the self-assembly is attracting great attention. The self-assembling diblock copolymers can produce various nanopatterns such as lamellar, cylindrical, or spherical nanostructures through self-organizing microphase separation. ${ }^{1}$ The polymer nanotemplate with periodic arrays of nanodomains can serve as a template for the fabrication of various nanostructures, providing an inexpensive, efficient, and simple method. Especially, block copolymer lithography has a higher potential for practical applications in nanoscale semiconductor microelectronics than other competing selfassembly techniques because the whole process and the materials are very compatible with standard semiconductor processes. $^{2}$

Among a variety of nanodomain arrays formed from diblock copolymers, cylindrical nanodomains perpendicular to the substrate are of particular importance for block copolymer lithography. Nanodots, ${ }^{3}$ nanopillars, ${ }^{4}$ and nanomembranes ${ }^{5}$ were fabricated through hybrid technology combining the self-assembly process with conventional topdown processes such as film deposition and etching. Black et $a l$. have demonstrated the fabrication of a metal-oxidesemiconductor capacitor with high charge storage capacity through the increase of surface area using diblock copolymer

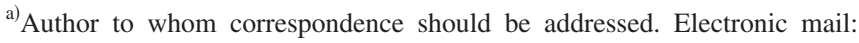
hyungjun@ postech.ac.kr as an etching mask and atomic layer deposition (ALD). ${ }^{6}$ Also, dense, ordered arrays of $\langle 100\rangle$-oriented Si nanorods were fabricated by nanoscale etching. ${ }^{7}$

To form the cylindrical nanohole arrays on any substrates, the interfacial energies between the diblock copolymer thin films and substrates should be precisely controlled. For this purpose, neutralization of the substrate surface is required to produce equal interfacial interaction between the substrate surface and each block of the copolymers. For the polystyrene-block-polymethylmethacrylate (PS- $b$-PMMA) diblock copolymer, the most common method of neutralization on the oxide surface of Si substrate has been the surface treatment by random copolymer brush (PS- $r$-PMMA) ${ }^{8,9}$ For this, the interfacial energies of polymers are controlled by end-grafting random copolymer brushes with proper styrene and methylmethacrylate molecular ratio. However, the application of this technique is limited to surfaces with hydroxyls such as Si oxide. Only recently, the surface neutralization of various substrates has been demonstrated by a cross-linking of an ultra thin layer of benzocyclobutene functionalized PS$r$-PMMA random copolymer. ${ }^{9}$

Self-assembled monolayers (SAMs) are thin organic films forming spontaneously on solid surfaces. Depending on the substrates, SAMs with proper head groups are required for the formation of stable monolayer. The SAMs of alkanethiols $\left[\mathrm{CH}_{3}\left(\mathrm{CH}_{2}\right)_{n-1} \mathrm{SH}\right]$ are formed on typically metal surfaces such as $\mathrm{Ag}, \mathrm{Au}$, and $\mathrm{Cu},{ }^{10,11}$ and SAMs of alkyltrichlorosilanes $\left[\mathrm{CH}_{3}\left(\mathrm{CH}_{2}\right)_{n-1} \mathrm{SiCl}_{3}\right]$ on $\mathrm{SiO}_{2}, \mathrm{Si}_{3} \mathrm{~N}_{4}$, and other oxide surfaces. SAMs have been shown to be useful for various applications. For example, they have been used for selective deposition of thin films, soft lithography, molecular electronics, the control of the wetting and friction behaviors, molecular electronics, and the protection of surfaces against corrosive environment. ${ }^{12-14}$ Especially, SAMs have been frequently used for controlling the wetting behavior of poly- 
mers on various surfaces. Peters et al. reported that the wetting behaviors of PS- $b$-PMMA diblock copolymers are dependent on the surface modification process for octadecyltrichlorosilane (OTS) SAMs. ${ }^{15}$ The wetting behavior was critically controlled by varying the grafting density of SAMs by tuning the surface energy. Based on a similar idea, the surface neutralization for the formation of cylindrical nanoholes was demonstrated using octadecyldimethyl chlorosilane (ODMS). ${ }^{16}$ Although a nanoporous PS template was fabricated by the formation of a partial monolayer of ODMS, the overall quality of the nanohole array, such as lateral periodicity and size distribution, was not high.

SAMs of 3-(p-methoxy-phenyl)propyltrichloro-silane [MPTS, $\mathrm{CH}_{3} \mathrm{OPh}\left(\mathrm{CH}_{2}\right)_{3} \mathrm{SiCl}_{3}$ ] were reported to produce substrates with nonselective interaction with PS and PMMA, producing perpendicular lamellar orientation in thin films of symmetric PS- $b$-PMMA. ${ }^{17}$ In this report, we achieved the surface neutralization of the various substrates including poly-Si and silicon nitride as well as oxide surface including native oxide, thermal oxide, and $\mathrm{ALD} \mathrm{HfO}_{2}$ by surface treatment using MPTS SAM. Well-ordered nanohole arrays comparable to those using random copolymer brushes were fabricated with various hole diameters ranging from 10 to 22 nm. Hybrid nanofabrication techniques combining selfassembly and top-down process including thin film deposition and etching were used to produce nanohole arrays in $\mathrm{SiO}_{2}$ layers and metal nanodot arrays.

\section{EXPERIMENTAL PROCEDURES}

Asymmetric diblock copolymer, PS- $b$-PMMA, having two molecular weights, $M_{n}=64800 \mathrm{~g} / \mathrm{mol}$ with polydispersity index of 1.08 and $\mathrm{M}_{n}=77000 \mathrm{~g} / \mathrm{mol}$ with polydispersity index of 1.09 , were used. The former was synthesized in the laboratory while the latter was purchased from Polymer Science and used as received. The molecular weight ratios between PS and PMMA were 27.8:72.2 and 28.6:71.4, respectively. The MPTS was purchased from Gelest and octadecyltrichlorosilane (OTS $>95 \%$ ) was purchased from Acro. A solution based method was used for SAM coating. Silicon wafers were cleaved to $1 \times 1 \mathrm{~cm}^{2}$ pieces and cleaned with piranha solution $\left(70 / 30 \mathrm{v} / \mathrm{v}\right.$ of concentrated $\mathrm{H}_{2} \mathrm{SO}_{4}$ and $30 \%$ $\mathrm{H}_{2} \mathrm{O}_{2}$ ) at $110{ }^{\circ} \mathrm{C}$ for $30 \mathrm{~min}$. Then they were rinsed water several times with deionized (DI) water. The cleaned substrates were immersed in a $1.0 \mathrm{mM}$ anhydrous toluene solution of MPTS (1\%) in an argon atmosphere glove box for 48 h. After the substrates were rinsed several times with chloroform, they were rinsed again with ethanol and blown dry with nitrogen. Thin PS- $b$-PMMA films were spin coated onto MPTS-coated substrate from 1.0 wt \% copolymer solution in toluene. The film thicknesses were measured by ellipsometer. The PS- $b$-PMMA films were then annealed under a vacuum at $180{ }^{\circ} \mathrm{C}$ for $24 \mathrm{~h}$ since the glass transition temperatures of the two polymer blocks are higher than $100{ }^{\circ} \mathrm{C}$ $\left(T_{g}=100{ }^{\circ} \mathrm{C}\right.$ for PS and $T_{g}=105{ }^{\circ} \mathrm{C}$ for PMMA). ${ }^{18,19}$ After annealing, the samples were exposed to UV radiation for 90 min under vacuum to degrade the PMMA blocks. Degraded

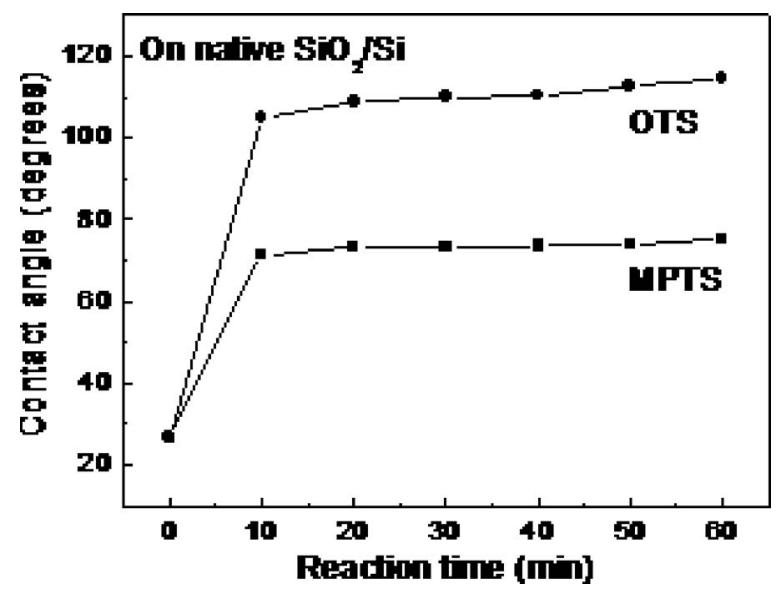

FIG. 1. Contact angle measurements of OTS (circles) and MPTS (squares) treated native $\mathrm{Si}$ oxide substrate as a function of immersing time. The concentration of SAM solution was $0.3 \%$ solution for each case.

PMMA was selectively removed by sonication in glacial acetic acid for $1 \mathrm{~min}$, followed by rinsing with DI water.

Cylindrical nanohole arrays were fabricated on various substrates, including silicon with native oxide, thermally grown $\mathrm{SiO}_{2}, \mathrm{ALD} \mathrm{HfO}_{2}$, low pressure chemical vapor deposition (LP-CVD) $\mathrm{Si}_{3} \mathrm{~N}_{4}$, and poly-silicon. To fabricate ordered nanoporous $\mathrm{SiO}_{2}$ templates using diblock copolymer, an inductively coupled plasma (ICP) was used to etch 20nm-thick thermally grown $\mathrm{SiO}_{2}$. The chuck power was constant at $50 \mathrm{~W}$ and the source power was $50 \mathrm{~W}$. To fabricate ordered $\mathrm{Au}$ nanodot arrays, a 10-nm-thick Au layer was evaporated onto the nanoporous PS templates. Prior to the metal deposition, we performed a $10 \mathrm{~s} \mathrm{O}_{2}$ plasma ashing $\left(\mathrm{O}_{2}\right.$ flow: $10 \mathrm{sccm}$, source power: $50 \mathrm{~W}$, pressure: $10 \mathrm{mtorr}$ ) in order to remove the SAMs at the bottom of the nanoholes. The PS template was removed using $N$-methylpyrrolidone (NMP; boiling point $202{ }^{\circ} \mathrm{C}$ ). The microstructure and surface morphology of the spin-coated films were investigated by high resolution field emission scanning electron microscopy (FE-SEM, JEOL JSM-7401F). The advancing contact angle was measured using a contact angle goniometer (Krüss, Germany). The cross-section of the metal nanodot was analyzed by high resolution transmission electron microscopy (HR-TEM, JEOL TEM 2010F).

\section{RESULTS AND DISCUSSIONS}

\section{A. Surface neutralization and the formation of nanohole array}

Figure 1 shows the advancing contact angle measurement of DI water droplet on the native $\mathrm{SiO}_{2}$ surface coated with SAMs of MPTS and OTS as a function of solution immersing time. Prior to SAM coating, the advanced contact angle of DI water on native $\mathrm{SiO}_{2}$ wafer was $26.6^{\circ}$, indicating the hydrophilic property of the surface. By coating the surface with OTS, the contact angle increases with dipping time to reach $115^{\circ}$, indicating the formation of fully hydrophobic surface due to the $\mathrm{CH}_{3}$ functional group of OTS. For MPTS, however, different behavior is observed. During the early 
stage of reaction time $\left(t_{r}\right)$ less than $10 \mathrm{~min}$, the contact angle rapidly increases to reach around $72^{\circ}$. Then the values slowly increase to saturate at $78^{\circ}$ within $2 \mathrm{~h}$ of reaction time. Further increase in reaction time did not produce changes in contact angle measurements, indicating the surface is fully adsorbed with MPTS molecules. In a previous report on the neutralization of surface with partial monolayer of ODMS, nonpreferential interaction of PS- $b$-PMMA was obtained for surfaces with contact angles between $65^{\circ}$ and $75^{\circ} .{ }^{16}$ Thus, the $73-78^{\circ}$ contact angles on the native $\mathrm{SiO}_{2}$ fully saturated with MPTS imply that the neutralization of the surface toward PS- $b$-PMMA was achieved. Similar contact angle measurements were reported, showing nonpreferential interaction of MPTS modified surface with PS and PMMA. ${ }^{17}$ The nonpreferential interaction of MPTS modified surface with PS was attributed to the similar functional head structure and that with PMMA to the polar interaction.

The wetting behavior of asymmetric PS- $b$-PMMA was investigated on various substrates. Thin films of PS- $b$-PMMA, with $35 \mathrm{~nm}$ thickness, were spin coated onto hydrophilic substrate $\left(\mathrm{SiO}_{2}\right)$, hydrophobic substrate (OTS coated surface), and MPTS coated surface. After spin coating with the diblock copolymer solution, the samples were annealed under a vacuum at $180{ }^{\circ} \mathrm{C}$. For hydrophilic and hydrophobic surfaces, the diblock copolymer films were dewetted, forming islands during annealing. The wetting behaviors of block copolymer films depending on the surface conditions are well documented. Peters et al. have shown that diblock copolymer films are segregated on OTS coated surfaces. ${ }^{15}$ If the surface is composed only of $\mathrm{CH}_{2}$ and $\mathrm{CH}_{3}$ groups, the diblock copolymer films are dewetted since the interfacial energy between PS and OTS coated surface $\left(\gamma_{\mathrm{PS} / \mathrm{OTS}}\right.$ $\left.=1.2 \mathrm{~mJ} / \mathrm{m}^{2}\right)$ is significantly lower than that between PMMA and OTS coated surface $\left(\gamma_{\mathrm{PMMA} / \mathrm{OTS}}=1.9 \mathrm{~mJ} / \mathrm{m}^{2}\right){ }^{20}$ However, for MPTS coated surface, flat films were formed, indicating the neutralization of the surfaces. Unlike OTS, the interfacial energies between PS or PMMA homopolymer and MPTS coated surface are similar to each other $\left(\gamma_{\text {PS/MPTS }}\right.$ $=2.21 \mathrm{~mJ} / \mathrm{m}^{2}$ and $\left.\gamma_{\text {PMMA } / \text { MPTS }}=2.19 \mathrm{~mJ} / \mathrm{m}^{2}\right) .{ }^{17}$

Figure 2 shows SEM images of PS nanohole arrays prepared by removing PMMA cyclindrical domains from annealed diblock copolymer thin films on MPTS coated $\mathrm{SiO}_{2} / \mathrm{Si}$ substrates. The SEM image of the sample dipped in MPTS solution for $24 \mathrm{~h}\left(t_{r}=24 \mathrm{~h}\right)$ shows misaligned holes and featureless regions [Fig. 2(a)]. However, for $t_{r}=48 \mathrm{~h}$, well-ordered cylindrical nanohole arrays are observed over entire surfaces [Fig. 2(b)]. For these samples, the molecular weight of PS- $b$-PMA was $64800 \mathrm{~g} / \mathrm{mol}$, resulting in $10 \mathrm{~nm}$ hole diameter on average. The hole size distribution was quite uniform and the hole ordering was comparable to that from PS- $b$-PMMA on random copolymer brush treated surface. ${ }^{21}$ From these results, we infer that although the contact angle measurements show saturation within a couple of hours of dipping time, the formation of high quality MPTS coated surface requires more time. It is well known that although SAMs are quickly formed spontaneously by the adsorption to a substrate, a slow reorganization process is often
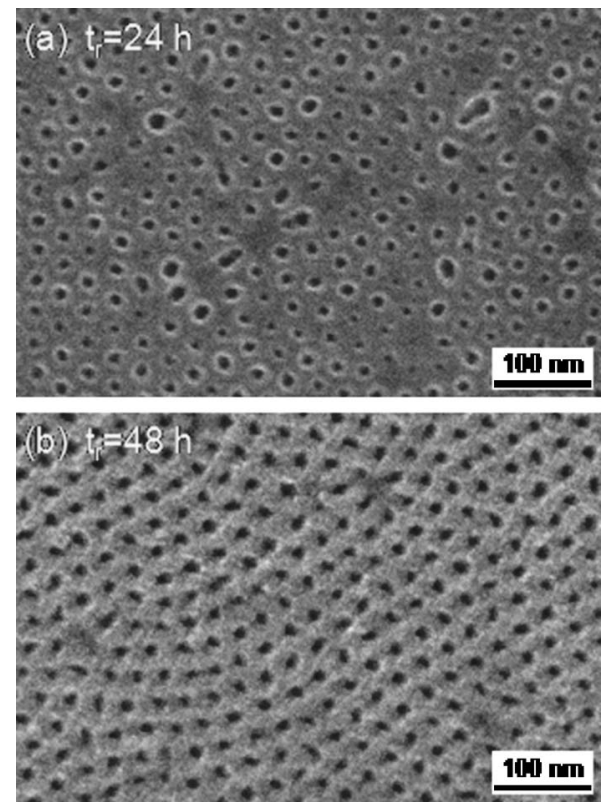

FIG. 2. SEM images of PS nanotemplate fabricated with different immersion times: (a) $24 \mathrm{~h}$ and (b) $48 \mathrm{~h}$. The substrate is $\mathrm{Si}$ with native oxide.

required to obtain well-ordered SAMs molecules. ${ }^{22}$ Since the MPTS molecule has an aromatic group, it requires a relatively long time for reorganization process compared to OTS, which is entirely composed of alkyl chain. However, it should be noted that the time required for the surface treatment with MPTS is comparable to that with random copolymer brush. ${ }^{8}$

The formation of the ordered cylindrical nanodomains critically depends upon several processing parameters such as polymer film thickness and annealing temperature. Figure 3 shows the film thickness versus spin speed with SEM images of PS nanohole arrays formed with thicknesses of (a) 22 $\mathrm{nm}$, (b) $38 \mathrm{~nm}$, and (c) $45 \mathrm{~nm}$. Well-ordered cylindrical nanodomains were only obtained for polymer thicknesses be-

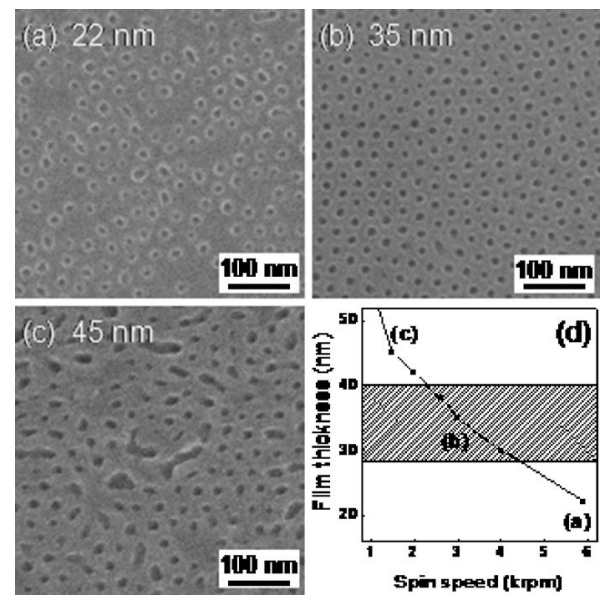

FIG. 3. SEM images of PS nanotemplate fabricated with PS- $b$-PMMA film thicknesses (a) $22 \mathrm{~nm}$, (b) $35 \mathrm{~nm}$, and (c) $45 \mathrm{~nm}$. (d) shows the film thickness measured by ellipsometer as a function of spin speed. The substrate is Si with native oxide. 


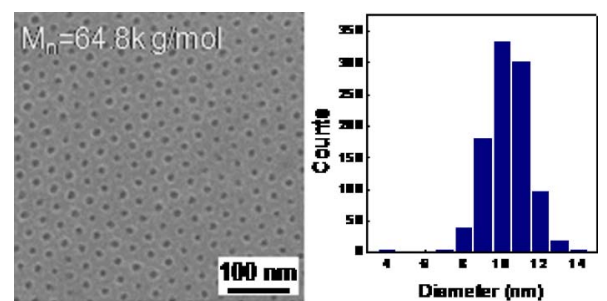

(a)

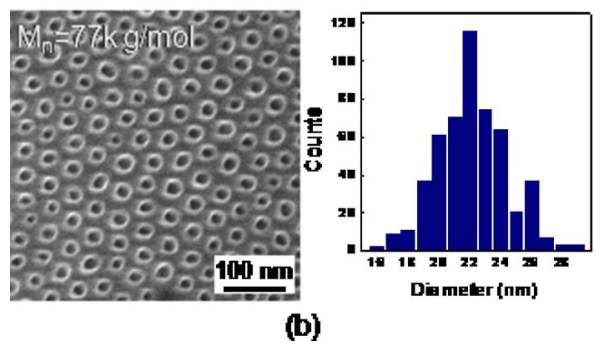

FIG. 4. SEM images and hole size distribution for PS- $b$-PMMA with molecular weights (a) PS:PMMA $=46.8 \mathrm{k}: 18 \mathrm{k}$ and (b) $P S: P M M A=52 \mathrm{k}: 22 \mathrm{k}$. The substrate is $\mathrm{Si}$ with native oxide.

tween 28 and $38 \mathrm{~nm}$. If the copolymer film is too thin, significant portions of the featureless region are formed, while poorly ordered holes with irregular shape are formed when it is too thick. These results are essentially similar to those on the nanohole arrays using diblock copolymer thin films on random copolymer brush treated surfaces. ${ }^{6}$ This similarity indicates that the formation of well-ordered nanohole arrays is not dependent on the surface neutralization method.

The diameter and separation distance of nanoholes in diblock copolymer template are determined by its molecular weight and molecular weight ratio between the two polymers. Figures 4(a) and 4(b) show SEM images of nanohole arrays from copolymer thin films with different total molecular weights and molecular weight ratios. As already mentioned above [shown in Fig. 2(b)], nanoholes with mean diameter of $10 \mathrm{~nm}$ were obtained for PS- $b$-PMMA block copolymer with total molecular weight of $64800 \mathrm{~g} / \mathrm{mol}$. By measuring about 1000 holes, the standard deviation of diameters was determined to be less than $0.9 \mathrm{~nm}$, indicating small diameter distribution. The center-to-center spacing of the holes was about $33 \mathrm{~nm}$. This result indicates that the formation of hole area density of $1.9 \times 10^{11} / \mathrm{cm}^{2}$ is easily achieved from the current process. For diblock copolymer with the total molecular weight of $77000 \mathrm{~g} / \mathrm{mol}$ [Fig. 4(b)], the mean pore diameter was $22 \mathrm{~nm}$ with a standard deviation of 2.4 $\mathrm{nm}$. The center to center spacing for this case was $46 \mathrm{~nm}$. It is known that there is a theoretical limitation in the smallest size attainable using microphase separation of diblock copolymer, since the copolymer is phase mixed when the $\chi^{N}$ $<10.49$, where $\chi$ is the segmental interaction parameter and $N$ is the number of monomers in the copolymer. ${ }^{23}$ While pore diameter down to $14 \mathrm{~nm}$ has been reported, ${ }^{24}$ the current result of $9 \mathrm{~nm}$ hole diameter is one of the smallest diameters ever reported from microphase separation.
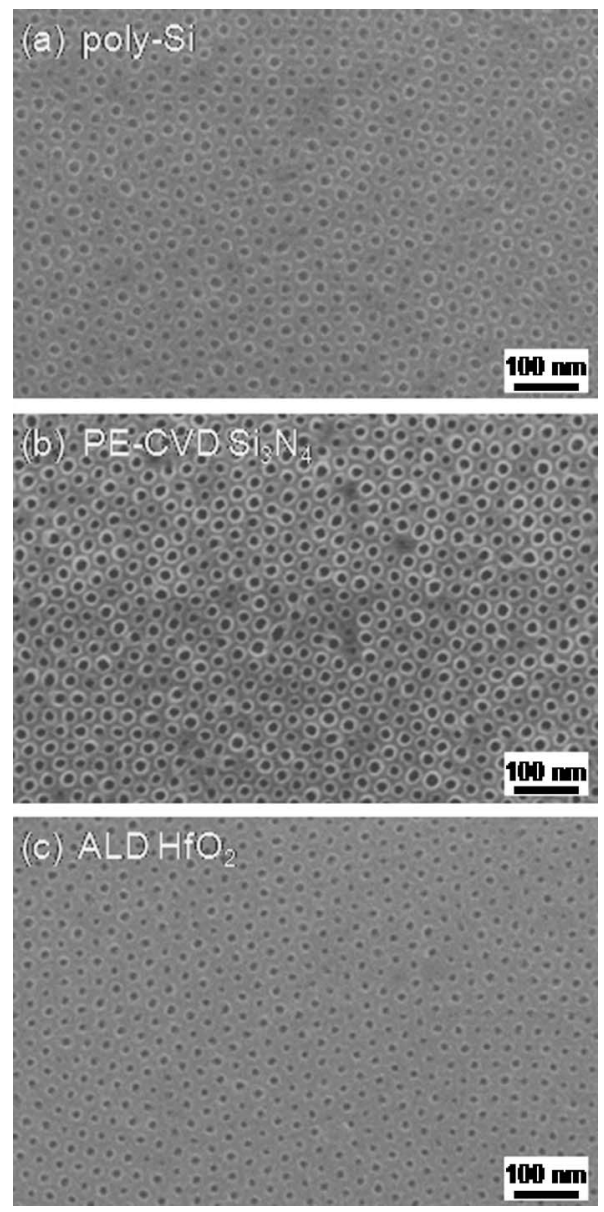

FIG. 5. SEM images of PS nanotemplate formed on (a) poly-Si, (b) PE-CVD $\mathrm{Si}_{3} \mathrm{~N}_{4}$, and (c) ALD $\mathrm{HfO}_{2}$.

\section{B. Hybrid process combining nanohole template and top-down processes}

To utilize the porous nanotemplate for various practical applications including microelectronic fabrications, the formation of templates on various substrates has great potential. The formation of high quality SAMs on various surfaces is already well demonstrated. Since the MPTS molecules have trichlorosilane head group at the end of the molecules, any surfaces with hydroxyl species are expected to be neutralized without difficulty. Figure 5 shows the polymer templates formed on (a) poly-Si (with native oxide), (b) $\mathrm{ALD} \mathrm{HfO}_{2}$, and (c) LP-CVD $\mathrm{Si}_{3} \mathrm{~N}_{4}$. For all these substrates, similarly well-ordered nanohole arrays were obtained without changing the process recipes. Thus, for any surfaces on which the SAM can be formed, the neutralization of the surface is achieved leading to the formation of vertically aligned cylindrical nanodomains. These results show the versatility of the current neutralization technique using MPTS. This is similar to the previous report showing the formation of the cylindrical nanohole arrays on silicon nitride, poly-Si, and borosilicate glass using the surface neutralization from random copolymer brush. ${ }^{6}$

One of the potential problems of polymer nanotemplate is that its thermal stability is not often good enough for various 

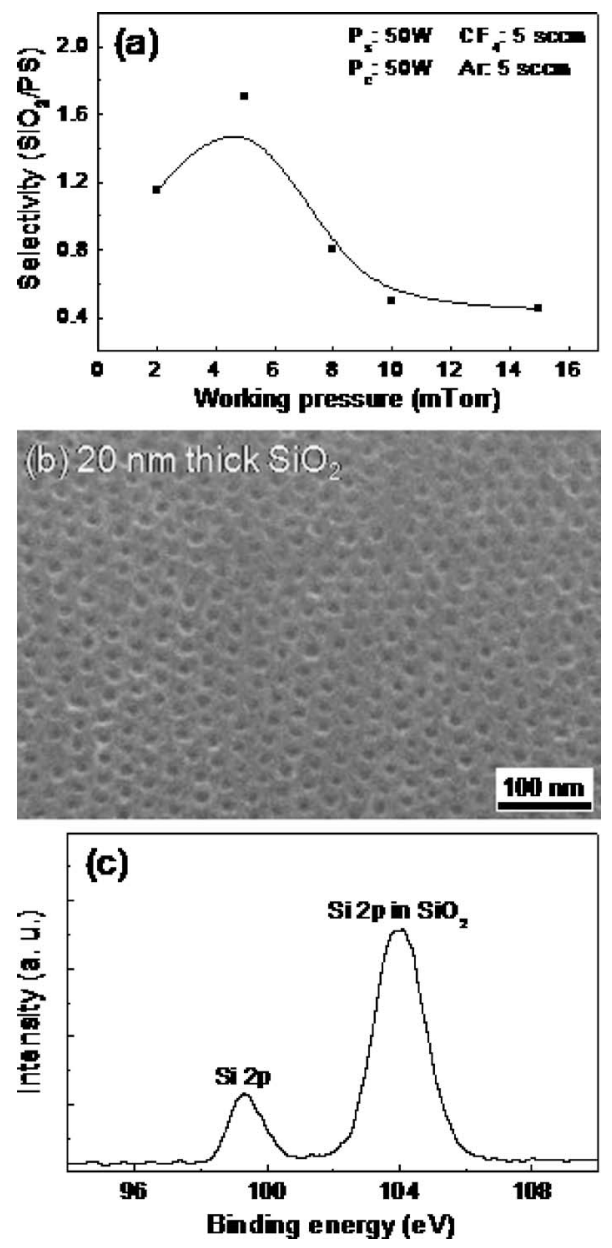

FIG. 6. (a) Etching selectivity between thermal $\mathrm{SiO}_{2}$ and PS blank films as a function of total working pressure showing the highest selectivity 1.7. (b) SEM image and (c) XPS Si $2 p$ spectrum of nanoporous $\mathrm{SiO}_{2}$ sample.

applications in the semiconductor industry. Thus, the pattern transfer to another layer with high thermal stability could be of great interest. We have transferred the nanohole array pattern of the PS template to underlying inorganic layers by conventional dry etching using the PS template as an etching mask. Here, the results on the fabrication of 20-nm-thick thermal $\mathrm{SiO}_{2}$ with nanoholes are described. However, it should be noted that a similar technique can be utilized to fabricate nanohole arrays on various materials, as long as the polymer template can be formed on the surfaces. In order to obtain proper etching conditions with high etching selectivity between $\mathrm{SiO}_{2}$ and PS, a blank PS film was prepared as a reference. The PS blank film was fabricated by spin coating and solvent drying at $40{ }^{\circ} \mathrm{C}$. Ar and $\mathrm{CF}_{4}$ mixed gas was used for enhanced etching selectivity. The etching process was optimized in terms of etching selectivity by changing various etching process parameters including source power $\left(P_{s}\right)$, chuck power $\left(P_{c}\right)$, Ar flow, $\mathrm{CF}_{4}$ flow, and total working pressure. Figure 6(a) shows the etching selectivity of $\mathrm{SiO}_{2}$ compared to blank PS film as a function of the total working pressure. The highest selectivity of 1.7 was obtained at the working pressure of $5 \mathrm{mTorr}$ with $8 \mathrm{sccm}$ of Ar flow and 5 sccm of $\mathrm{CF}_{4}$ flow at $P_{s}=P_{c}=50 \mathrm{~W}$. Since the nominal thick- ness of the PS template is $30-40 \mathrm{~nm}$, the $\mathrm{SiO}_{2}$ layer with thickness up to $50-70 \mathrm{~nm}$ can be etched at these etching conditions. However, it should be noted that the blank PS film used in the current experiments probably has less etching resistance than the PS template, which went through the high temperature annealing at $180{ }^{\circ} \mathrm{C}$. Thus, the nanohole array pattern formation to thicker $\mathrm{SiO}_{2}$ layer should be possible.

Figure 6(b) shows SEM image of the $\mathrm{SiO}_{2}$ layer with nanohole array, which was formed by pattern transfer. The pattern in the PS template was exactly duplicated in the $\mathrm{SiO}_{2}$ layer. Since it was difficult to directly observe if the holes were generated down to the bottom of the $\mathrm{SiO}_{2}$ layer, we carried out XPS analysis on the prepared sample. Figure 6(c) shows the XPS spectrum in the Si binding energy region. We clearly see significant $\mathrm{Si}$-Si bonds from the exposed layer of $\mathrm{Si}$ substrate. Since the electron escape length in the $\mathrm{SiO}_{2}$ layer is only $2.86 \mathrm{~nm},{ }^{25,26}$ the observation of $\mathrm{Si}-\mathrm{Si}$ bonds implies that the $\mathrm{Si}$ substrate is exposed in the nanohole region.

As another application of the PS nanotemplate, a high density metal nanodot array was fabricated. High density arrays of nanodots exhibit intriguing electrical, optical, and biological characteristics, which have potential applications in nonvolatile memories, hard disk drive, laser, and cell staining. ${ }^{27-30}$ As an example, we fabricated Au nanodot arrays on Si substrate. The gold thin film was evaporated on top of the PS template. In initial experiments, we have found that the adhesion of $\mathrm{Au}$ to the surface inside of the nanohole is not strong enough, due to the presence of SAM on the surfaces. Thus, we have removed the SAM by using a $10 \mathrm{~s}$ oxygen plasma treatment, which minimized the degradation of the PS template. For effective lift off process, a solvent with high boiling point, 1-methyl-2-pyrrolidone (NMP), was used. Figure 7(a) is a top-down SEM image of $\mathrm{Au}$ nanodot array. Well defined hexagonal arrays of gold nanodots were formed. The average diameter of gold nanodot is $9 \mathrm{~nm}$, which is similar to that of the holes in the PS template. From the HR-TEM image [Fig. 7(b)], we observed that the shape of the Au dot is spherical, not hemispherical. This is thought to be due to dewetting of $\mathrm{Au}$ on the $\mathrm{SiO}_{2}$ surface. Most of the Au nanodots are single crystal as seen in Fig. 7(b). Although only the formation of Au nanodot arrays was demonstrated in this study, this method can be applied to produce nanodot arrays of various materials, which would provide vast opportunities in many applications including nanowire catalyst, plasmonics, and nanocrystal memory.

\section{CONCLUSIONS}

The SAMs of MPTS were used to neutralize the substrate producing nonpreferential interactions with both PS and PMMA. SAM based surface neutralization has produced PS templates with cylindrical nanohole arrays of good ordering and versatility comparable to random copolymer brushs. Inorganic nanotemplates were produced by combing the selfassembly and dry etching process. Also, a simple route to make metal nanodot arrays was demonstrated. 

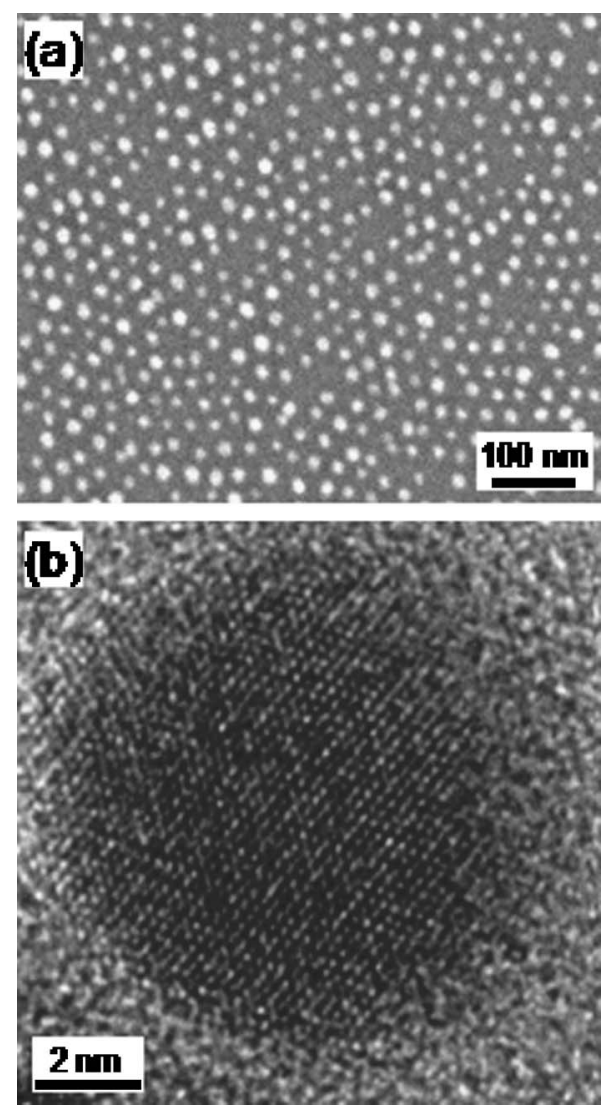

FIG. 7. (a) SEM image of Au nanodot array on Si substrate and (b) high resolution TEM image of a gold nanodot.

\section{ACKNOWLEDGMENTS}

This work was supported by Korea Research Foundation (Basic Research Promotion Fund Grant No. KRF-2006-311D00114 and MOEHRD Grant Nos. KRF-2005-005-J13102, KRF-2007-331-D00243), the Korea Science and Engineering Foundation (KOSEF) grant funded by the Korean government (MOST) (No. R01-2007-000-20143-0), Nano R\&D Program through the Korea Science and Engineering Foundation funded by the Ministry of Science \& Technology (Grant No. 2007-02864), and POSTECH Core Research Program. The authors gratefully acknowledge the financial support of the System IC 2010 Program, Korea Electronic Tchnology Institute, and thank J. W. Park in POSTECH for help in contact angle measurements. S.J.K. and W.J.M. were financially supported by the second stage of the Brain Korea 21 Project in 2007.
${ }^{1}$ R. A. Segalman, Mater. Sci. Eng., R. 48, 191 (2005).

${ }^{2}$ C. T. Black, Appl. Phys. Lett. 87, 163116 (2005).

${ }^{3}$ S. Xiao, X. Yang, E. W. Edwards, Y.-H. La, and P. F. Nealey, Nanotechnology 16, S324 (2005).

${ }^{4}$ D. Zschech, D. H. Kim, A. P. Milenin, R. Scholz, R. Hillebrand, C. J. Hawker, T. P. Russell, M. Steinhart, and U. Gösele, Nano Lett. 7, 1516 (2007).

${ }^{5}$ C. K. Shin, G. Maier, B. Andreaus, and G. G. Scherer, J. Membr. Sci. 245, 147 (2004).

${ }^{6}$ K. W. Guarini, C. T. Black, K. R. Mikove, and R. L. Sandstrom, J. Vac. Sci. Technol. B 19, 2784 (2001).

${ }^{7}$ C. T. Black, K. W. Guarini, K. R. Mikove, S. M. Baker, T. P. Russell, and M. T. Tuominen, Appl. Phys. Lett. 79, 409 (2001).

${ }^{8}$ P. Mansky, Y. Liu, E. Huang, T. P. Russell, and C. Hawker, Science 275, 1458 (1997).

${ }^{9}$ D. Yeol, K. Shin, E. Drockenmuller, C. J. Hawker, and T. P. Russell, Science 308, 236 (2005)

${ }^{10}$ P. E. Laibinis, G. M. Whitesides, D. L. Allara, Y.-T. Tao, A. N. Parikh, and R. G. Nuzzo, J. Am. Chem. Soc. 113, 7152 (1991).

${ }^{11}$ A. S. Blum, J. G. Kushmerick, D. P. Long, C. H. Patterson, J. C. Yang, J. C. Henderson, Y. Yao, J. M. Tour, R. Shashidhar, and B. R. Ratna, Nat. Mater. 4, 167 (2005).

${ }^{12}$ M. H. Park, Y. J. Jang, H. M. Sung-Suh, and M. M. Sung, Langmuir 20, 2257 (2004).

${ }^{13}$ H. B. Akkerman, P. W. M. Blom, D. M. de Leeuw, and B. de Boer, Nature (London) 441, 69 (2006).

${ }^{14}$ F. P. Zamborini and R. M. Crooks, Langmuir 14, 3279 (1998).

${ }^{15}$ R. D. Peters, X. M. Yang, T. K. Kim, and P. F. Nealey, Langmuir 16, 9620 (2000).

${ }^{16}$ A. Niemz, K. Bandyopadhyay, E. Tan, K. Cha, and S. M. Baker, Langmuir 22, 11092 (2006).

${ }^{17}$ B. H. Sohn and S. H. Yun, Polymer 43, 2507 (2002).

${ }^{18}$ Y. P. Koh, G. B. Mckenna, and S. L. Simon, J. Polym. Sci., Part B: Polym. Phys. 44, 3518 (2006).

${ }^{19}$ B. B. Sauer and Y. H. Kim, Macromolecules 30, 3323 (1997).

${ }^{20}$ R. D. Peters, X. M. Yang, T. K. Kim, B. H. Sohn, and P. F. Nealey, Langmuir 16, 4625 (2000).

${ }^{21}$ C. T. Black and K. W. Guarini, J. Polym. Sci., Part A: Polym. Chem. 42, 1970 (2004).

${ }^{22}$ J. C. Love, L. A. Estroff, J. K. Kriebel, R. G. Nuzzo, and G. M. Whitesides, Chem. Rev. 105, 1103 (2005).

${ }^{23}$ L. Leibler, Macromolecules 13, 1602 (1980).

${ }^{24}$ T. Xu, H.-C. Kim, J. DeRouchey, C. Seney, C. Levesque, P. Martin, C. M. Stafford, and T. P. Russell, Polymer 42, 9091 (2001).

${ }^{25}$ K. Takahashi, H. Nohira, K. Hirose, and K. Hattori, Appl. Phys. Lett. 83, 3422 (2003).

${ }^{26}$ T. Hattori, K. Azuma, Y. Nakata, M. Shioji, T. Shiraishi, T. Yoshida, K. Takahashi, H. Nohira, Y. Takata, S. Shin, and K. Kobayashi, Appl. Surf. Sci. 234, 197 (2004).

${ }^{27}$ Y.-H. Lin, C.-H. Chien, C.-T. Lin, C.-Y. Chang, and T.-F. Lei, IEEE Trans. Electron Devices 53, 782 (2006).

${ }^{28}$ K. Naito, H. Hieda, M. Sakurai, Y. Kamata, and K. Asakawa, IEEE Trans. Magn. 38, 1949 (2002).

${ }^{29}$ A. E. Zhukov, A. R. Kovsh, V. M. Ustinov, D. A. Livshits, P. S. Kop'ev, Z. I. Alferov, N. N. Ledentsov, and D. Bimberg, Mater. Sci. Eng., B 74, 70 (2000).

${ }^{30}$ S. Le Gac, I. Vermes, and A. van den Berg, Nano Lett. 6, 1863 (2006). 